\title{
Changing Digital Culture and its ImPaCt ON WoMen
}

\author{
Sunita Sharma \\ Maniben Nanavati Women's College \\ sunitasharma12@yahoo.co.in
}

\begin{abstract}
Information and Communication Technologies (ICTs), including the Internet, are increasingly influential across all aspects of life. Women's Equality is one of the 17 Sustainable Development Goals, but also integral to all dimensions of Inclusive and Sustainable Development.

E-Commerce also known as internet commerce refers to the buying and selling of goods and services using the internet. The companies of the future, through the rules of electronic commerce, form a new productive framework. These digital transformations have managed to generate new labour paradigms. The paper lists the new jobs profile created by technology. It attempts to find answers to, whether the women are going to benefit from the changes that take place in the labour market and in the economy in general? And is there a new window of opportunity? Or is it simply more of the same? It concludes by giving suggestions, so that the ladder of women development is not thrown away.
\end{abstract}

Keywords: Internet and gender, Labour paradigms, Algorithms and gender

\section{INTRODUCTION}

Information and Communication Technologies (ICTs), including the Internet, are increasingly influential across all aspects of life. ICTs have boosted growth and expanded opportunities.

Women's Equality is one of the 17 Sustainable Development Goals, but also integral to all dimensions of Inclusive and Sustainable Development. States have committed to striving for universal and affordable access to the Internet in least developed countries by 2020 (target 9(c) of the Goals), as well as to ensure that women and men have equal access to basic services, including new technology by 2030 (target 1.4).

The digital transformations, we have been living in the production processes, managed to generate new labour paradigms. The gender digital divide is a consequence of disparities in ICT access and use, which reflects discrimination faced by women in society.

This research paper - lists the new jobs created by technology and attempts to find answers to the questions whether the women going to benefit from the changes that take place in the labour market and in the economy in general and does e-commerce open a new window of opportunity; or is it simply more of the same. The paper concludes by giving suggestions to reprogram technology.

\section{MATERIALS AND METHOD}

\subsection{E-COMMERCE AND THE JOBS OF FUTURE}

E-Commerce also known as electronic commerce or internet commerce refers to the buying and selling of goods and services using the internet, and the transfer of money and data to execute these transactions.

The rules applicable to companies so as to operate economic exchanges through the internet can be summarised into no commercial presence requirement for companies operating through internet, no technology transfer requirement as a condition to operate, no obligations for companies to abide by the decisions of local courts regarding consumer rights and protections, no obligations to pay taxes for data transfers, and no access to or localisation requirements for data in the country where it is collected.

These five points are a part of diverse international agreements on services and e-commerce proposes, raised at the meeting of the World Trade Organisation (WTO) and Free Trade Agreements. All companies will fall under the scope of these five rules, whether they are web portals or not.

The companies of the future through the rules of electronic commerce, form a new productive framework, where they no longer own the stock of the product, they do not have employees or commercial offices. The companies that outsource everything, the workers are disguised under the name of clients or entrepreneurs. The jobs of the future can be divided into four broad categories: new jobs created by technology, jobs affected (modified/replaced) by technology/Artificial Intelligence (AI), The entrepreneurs and platform workers - outsourced, and the digitally excluded.

The New Jobs created by technology demand workers to devote themselves 7 days a week, 24 hours a day to have availability for the platform in order not to have negative ratings, as these end up 
being detrimental to their reputation and level of sale. Nowadays by multinational companies, the workers qualification systems are imposed, where each time the buyer has less degree of freedom to qualify and there is an automatic system that measures, whether the seller met the imposed standard.

The algorithms of a web worker imposes rules, from how to make a shipment, to how to respond to a message or make a publication, everything, absolutely is parameterised by the platform and the algorithm automatically judges the work performance based on the imposed standards.

The second subgroup is the jobs that are going to be modified or replaced by Artificial Intelligence: we find to a large extent jobs that are destroyed daily and replaced by machines, with the creation of new repair posts, design, maintenance and systematisation of data generated by these machines. These employees who must adapt to the new reality suffer a double impact. On one hand they are left without work, but on the other they find many difficulties of reintegration in the market. Since they find that new jobs require special skills adopted. They end up focusing on the service sector and above all on platform jobs, in order to find a quick solution to the unemployment drama, being very expensive to receive the necessary training to readjust and re-enter the job market in higher qualified positions.

The third subgroup includes the entrepreneurial paradigm and the platform workers: Companies have managed to generate a new type of outsourced worker, the entrepreneur. The demands that capitalism was able to impose on workers will make it increasingly incompatible to sustain a sustainable private and working life in the long term. The idea of working from home has led to dismemberment of production in small units, has led to entrepreneurial workers in the most diverse areas e.g. in textiles, where there used to be large clothing manufacturing buildings, today we see isolated workshops that deliver production weekly and work in groups of no more than 3 to 4 people in the garage of a house. The entrepreneur has only one comfort, that is to be able to stay in his home, but he does not enjoy and benefit for his work, beyond the salary, since the companies demand limited deadlines, without holidays, sick leaves, medical insurance, retirement or bonus.

Another category is Platform workers, an increasingly growing sector in the economy e.g. Amazon, the platforms of the most diverse are created every day from educational or various services such as UBER, to platforms of lawyers, translators, language courses, graphic design and all that we can imagine. Companies generate platforms to bring markets closer together and outsource employment in an increasingly dynamic capitalism.

Finally we have digitally excluded jobs. This includes jobs that cannot be replaced by technology e.g. Care Jobs. Women traditionally lead this sector; now find fierce competition from men to enter this market massively in order to keep a job that does not require technical transformation. In fact today we see male nurses, teachers or baby sitters. According to US Bureau of Labor Statistics (BLS) 2019, 12 percent of registered nurses are men, up from 2.7 percent in 1970. Similarly child care male teachers rose to 6.3 percent in 2017 from 3.2 percent in 1995(BLS). The National Education Association (NEA) School Statistics 2018 Reports, nearly one - fourth of the teachers in US public schools in 2017 were men.

This sector is booming with the growing life expectancy worldwide as a result of improved health, some countries find little work force dedicated to care jobs, further enhancing the massive entry of men to this sector. These traditionally female jobs probably will not be as such in the future, the women will benefit from technological transformation as the jobs in this sector will grow and not be replaced. In fact UNCTAD ensures that where more highly qualified jobs are going to be created throughout the economy, it will be in those related to technology and telecommunications, where only 16 percent of workers are women and the percentage does not seem to rise over the years. After reviewing new labour paradigms created by e-commerce let us now look at what do women expect from the changes that take place in the labour market and in the economy in general.

\subsection{E-COMMERCE AND BENEFITS TO WOMEN}

E-commerce is gender neutral. It does not matter who is behind selling or delivering a service, payment is equal for everyone. E-commerce is a powerful tool to reduce the pay gap between men and women.

E-commerce has benefitted women worldwide. It would impact positively on the gender gap. The working groups on gender and electronic e-commerce have been established at WTO and UNCTAD.

The benefit to women from the new forms of remote or entrepreneurial labour is there because they will be able to work from home without leaving household chores unattended. This will articulate their professional work and maternity. The internet has opened a world of opportunities for all of us. 
There is a wave of optimism towards electronic commerce, as because of internet approximately 60 percent of women in developing countries. Ensure that having more flexible hours has allowed facilitated employment and reconciliation of personal and professional life. The reality is that the social transformation that we are seeing worldwide, with the empowerment of women, the age gap and equal opportunities, has been incorporating women in a massive way into the labour market. Therefore it is very pretentious to award the kindness to electronic commerce; in fact, technology is one more vehicle that women have found. The engine is global social change.

The technology is neutral to the issue of gender with respect to earnings. A web worker earns the same regardless of gender. The requirements of the client must be met at the time and day client wants.

The modern jobs are positive to close the gender gap because the platform doesn't care if you are male or female. The pay is closely linked to the level of effort put by the entrepreneur worker. Therefore, the system is neutral to the issue of gender.

The empowerment of women and the increasing participation of women in web spaces and entrepreneurial jobs are due to the difficulty they have had in reconciling work and personal life. In the dream of achieving that both realities can co-exist, women find in entrepreneurial work a difficult and hard opportunity.

Automation of jobs will benefit women worldwide because care service jobs where workers are predominantly women, are most difficult to replace with machines. So, the women will be least adversely affected by the labour readjustments, the changes in the production to new technology means demands.

\section{RESULTS AND DISCUSSION}

An increasing number of appliances are now equipped to operate automatically or remotely on the basis of information we give them. From vacuum cleaner that sweeps the house by itself to a ring-bell with in-built camera that can be answered from the cell phone more and more things are currently digitalised and we are moving towards an economy based on AI that will facilitate many of our daily life routines. But the question is who controls the modern appliances and who give them the household information that allows them to operate. In example, if fridge runs out of milk, who it will alert of this fact. If the household needs vacuum cleaner, who is programming the time at which that will be done, if bread needs to be baked for tomorrow, and who prepares the bread baking machine.

Products that facilitate housewives life are advertised, if appliance sends the information to the woman, because it was programmed that way, the man will never know that there was no milk in the fridge, nor that vacuum cleaner stopped working or the ring bell sounded and needs to be answered. So these technologies end up being additional weight on women's daily lives, having to withstand permanent interruptions in their workday from notifications that reinforce and overload them with additional household responsibilities. So to say that e-commerce, technology has benefitted women and contributes to reduce gender gap, is incorrect as only existence of a washing machine has done that, but the washing machine will be set by a woman. For the case, a dishwasher is neutral, it can be turned on by anyone, but paradoxically, it's the women who, on an average, takethe charge of starting it. So the situation does not change, but continues to remain the same. The household work is shared task of both husband and wife, but the statements that women as remote labour will be able to work from home without leaving household chores unattended, stretches the role of women in society as has been traditionally taken for granted.

Women are usually doing the household shopping (clothes, food, school materials, etc.). The household shopping is predominantly a woman dominated market. In fact 76 percent more of the household chores, with no payment, spending more than 5 hours a day is spent by women on online sales and shopping. The consequence of this is that advertisements land directly on email boxes of women, their Facebook pages, and their search engines. This is a step towards reinforcing the idea that household chores are a women's task. The men do not get advertisements, their new role is not facilitated nor is the idea reinforced that household chores have to be done by anyone mothers or fathers regardless of gender.

Women are discriminated against daily, violated, insulted, and mistreated in all social networks. On web probably because they do not have to face the victims directly, the violence is greater. Women are criticized for their physique way of saying things, for the way they run their business and even for working. There is no digital neutrality. We should be claiming an algorithm that takes into account notorious overload on women.

Algorithms generated on the basis of big data are now replacing entire production. These algorithms are prepared for social changes. They are developed on the basis of past time information. They reinforce and repeat humanity's history. Web based human resources search engines are good 
example of how these algorithms actually expand the gender gap. Companies are already replacing their human resource departments for algorithms - specifying that they will only hire people that have been successful in their work. Successful is any employee that has worked at least three years in a company and that has been promoted at least once during that time. Research study conducted shows that algorithm would capture the profiles of those that fulfil such conditions. These people are men, 25-35 years old with higher level education. Women fall outside the parametric. The reason is that they are victims of discrimination, violence and labour harassment. In short, the algorithm merely replicates the history of gender violence and reproduces it.

On an average woman suffer more, because they continue to take care of domestic work, taking children to the doctor, making purchases, cleaning and attending to emotional and family care demands. The algorithm does not see whether, you have a sick child or you had to go out to do shopping. Your requirements must be met at the time and day the client wants. Thus to say that technology is neutral to the issue of gender, with respect to earnings is incorrect as men on an average earn more than women. The above findings are also supported by a study, which says that men earn on average between 15-25 percent more than women depending on the country. Therefore, in reality women obtain less income from remote work than men.

These technologies end up being additional weight on women's daily lives. So to say that ecommerce, technology has benefitted women and contributes to reduce gender gap is incorrect.

\section{CONCLUSION}

The debate is broad and the consequences of the technological changes are not easy to see and analyse. The social problems of the society are not solved only by introducing new forms of productions in society. They replicate the realities that are already present in the economy. The unequal society will not solve gender problems magically overnight only by enjoying technological transformations.

The debate around equality must continue, so that technology does not do what it was programmed for: to reinforce inequality between men and women. A more fair society is necessary. Let us reprogram it with consciousness raising and debate.

\section{REFERENCES}

Avila, R., Brandusescu, A., Freuler, J., \& Thakur, D. (2018). Artificial Intelligence: Open questions about gender inclusion. Retrieved from http://webfoundation.org/docs/2018/06/AI-Gender.pdf.

Ganesh, M. (2018). Data and Discrimination: Fintech, Biometrics and Identity in India. Retrieved from https://thesocietypages.org/cyborgology/2018/01/25/fintech-aadhaar-and-identity-in-india/

Gurumurthy, A. (2016). Beyond the offline-online binary - why women need a new global social contract. Retrieved from https://www.genderit.org/feminist-talk/beyond-offline-online-binary$\% \mathrm{E} 2 \% 80 \% 93$-why-women-need-new-global-social-contract

Scasserra, S. (2018). E commerce, Future of labor and its impact on women. Retrieved from https://itforchange.net/draft/e-commercer-future-of-labor-and-gender-gap.pdf

Valente, M., \& Neris, N. (2018). Are we going to feminise the internet? - Sur - International Journal on Human Rights. Retrieved from https://sur.conectas.org/en/are-we-going-to-feminise-theinternet/ 
